\section{Totales Qualitätsmanagement}

U. Zimmermann ${ }^{1}$ und A. Steinhorst ${ }^{2}$

${ }^{1}$ Gesundheit / Forensik, Deutsche Akkreditierungsstelle

GmbH (DAkkS), Frankfurt, Deutschland

${ }^{2}$ EA Secretariat, Paris, Frankreich

\section{$\operatorname{Synonym(e)~TQM~}$}

Englischer Begriff total quality management
Definition Auf der Mitwirkung aller ihrer Mitglieder (jegliches Personal in allen Stellen und allen Hierarchieebenen) beruhende Führungsmethode einer Organisation, die Qualität in den Mittelpunkt stellt und durch Zufriedenstellung der Kunden auf langfristigen Geschäftserfolg sowie auf Nutzen für die Mitglieder der Organisation und für die Gesellschaft zielt.

\section{Literatur}

DIN EN ISO 8402:1995 „Qualitätsmanagement und Qualitätssicherung - Begriffe“" 